\title{
Analysis of DC breaker requirements for different HVDC grid protection schemes
}

\author{
B. Geebelen, W. Leterme, D. Van Hertem ${ }^{\dagger}$ \\ ${ }^{\dagger}$ KU Leuven Dept. Esat Div. Electa/EnergyVille, Leuven, Belgium \\ bartgeebelen@gmail.com,willem.leterme@esat.kuleuven.be,dirk.vanhertem@esat.kuleuven.be
}

Keywords: DC breaker, fault transient, HVDC grid, power system protection

\begin{abstract}
This paper compares the DC breaker requirements for different DC breaker protection schemes for high voltage direct current (HVDC) grids. DC breakers are essential for DC grid protection as they can provide a selective and fast protection. The DC breakers experience challenging operation conditions which results in an increased cost to meet the breaker requirements. The breaker requirements are strongly determined by the employed protection system. As such, the solution of breaker and protection system is strongly linked. A solution to reduce the requirements is by choosing the best suited protection method concerning the breaker requirements. In this paper, two proposed protection methods and their breaker requirement are explained and compared. The first protection method is a full selective DC protection (FSP) similar to AC protection. A second option, referred to as open grid protection (OGP), is by opening each breaker independently in case of a fault. The reduction potential of the dissipated energy requirement of the DC breaker of both protection schemes is simulated by applying a pole-to-ground DC fault in a four-terminal network with modular multi-level converters. The required energy for the different protection schemes is investigated for different current ratings and switching times. All studies have been performed using PSCAD/EMTDC. From the advantages and drawbacks of these two protection schemes, a new protection method is proposed.
\end{abstract}

\section{Introduction}

High voltage direct current (HVDC) grids are considered to be the preferred technology for the transmission of bulk power over longer distances [1]. Compared to point-to-point connections, an HVDC grid improves the reliability of power transfer from remote renewable energy sources to the mainland in a cost efficient manner. However, HVDC grid protection is currently seen as a major technical challenge.

Because of the different fault behavior compared to an $\mathrm{AC}$ fault, conventional AC breakers lack the capability to interrupt DC faults. The main difference lies in the absence of zero crossing of a DC fault current and the fundamentally faster fault current rise. An AC breaker uses the zero crossing to open the mechanical breakers and to quench the arc between the two contacts. By opening the contacts during commutation, the overall energy dissipation in the breaker is reduced [2]. Therefore DC protection requires adapted DC breakers and new protection methodologies to interrupt the fault. Secondly, the fault current rises an order of magnitude faster than AC faults.

This paper compares the DC breaker requirements for two protection methods: full selective protection and open grid protection. The fast rate of rise of the fault current is diminished by placing series inductors of which the size is determined by the DC breaker requirement. First, important DC fault and DC breaker parameters are described. Secondly, the simulation network is further elaborated. Next, the two protection methods and their influence on the breaker requirements are investigated.

\section{DC fault}

DC faults are characterised by a high rate of rise and a high steady-state current, which requires fast interruption [3]. The fast interruption time is a major parameter in DC breaker design. This time can be increased by placing inductors in series with a DC breaker, decreasing the rate of rise of the fault current. The disadvantage of this method is the increase in stored energy in the network which the breakers need to dissipate.

The DC fault transient is in the millisecond range dominated by travelling waves. These waves propagate through the network with a certain velocity $v$, which is given by [4]:

$$
v=\frac{1}{\sqrt{L C}}
$$

with $l$ and $C$ the inductance and capacitance of the transmission line [5]. As fault clearing must occur in the same time range as fault propagation throughout the network, the propagation delay becomes important for the choice of protection scheme and the fault detection method.

Fig. 1 visualizes the propagation delay of a fault occuring in a DC network consisting of three radially connected buses. The 


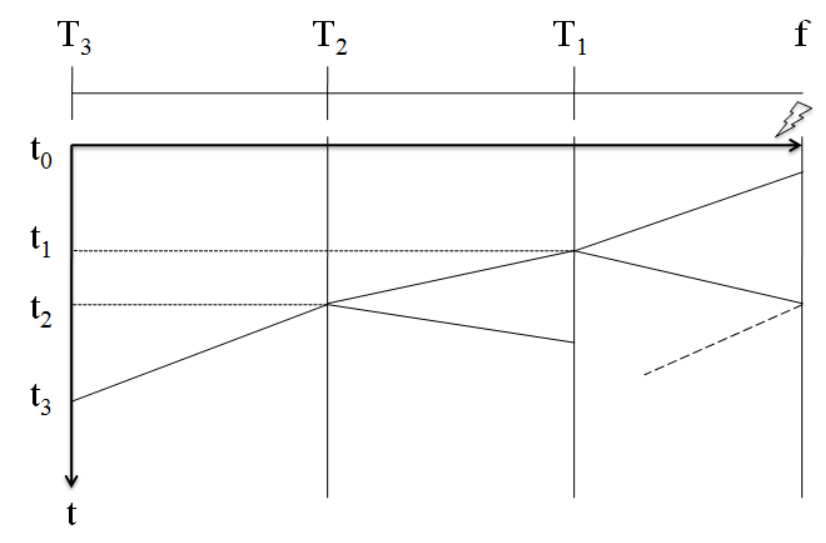

Fig. 1: Bewley diagram of wave propagation in a three-bus radial network.

fault $\mathrm{f}$ occurs on a transmission line connecting $T_{1}$ to the remainder of the grid. The traveling waves emanating from the fault location first reach bus $T_{1}$ after a certain time delay depending on the distance of the fault to bus $T_{1}$. Then, the traveling wave reaches buses $T_{2}$ and $T_{3}$ at times $t_{2}$ and $t_{3}$, depending on the propagation delay over the lines connecting the buses.

For underground cables, the propagation speed is in the order of half to two thirds the speed of light. Typical propagation delays in cable networks with distances of hundreds of kilometres thus lie in the millisecond scale.

\section{DC breaker parameters}

This section gives the main DC breaker parameters, based on the construction of a generic hybrid breaker in Fig. 3 on a simple DC circuit shown in Fig. 4 [6] [7].

Different DC breaker concepts have been developed, of which a hybrid breaker (combining a mechanical and power electronic switch) is the most prominent one [8]. Although the hybrid breaker construction can cope with requirements such as a fast commutation time and a sufficient counter voltage probability, current DC breaker designs are challenged to interrupt very high fault currents and to dissipate a large amount of energy in the breaker.

The breaker sequence during fault is given in Fig. 2 . If a fault occurs, an ultra fast (low voltage) switch in series with the mechanical switch opens and the current is redirected to the commutating branch to interrupt the fault. The low voltage switch itself is not capable of interrupting the DC current. The interruption are performed by the commutation branch. After the fault is diverted, the mechanical breaker can be opened and the commutation branch is switched of. The fault is isolated but the energy remains to be dissipated. This is done by a third parallel branch, the absorption branch, which contains an arrester to dissipate the energy and to create a counter voltage. When all the energy is dissipated, the hybrid breaker actions are completed.

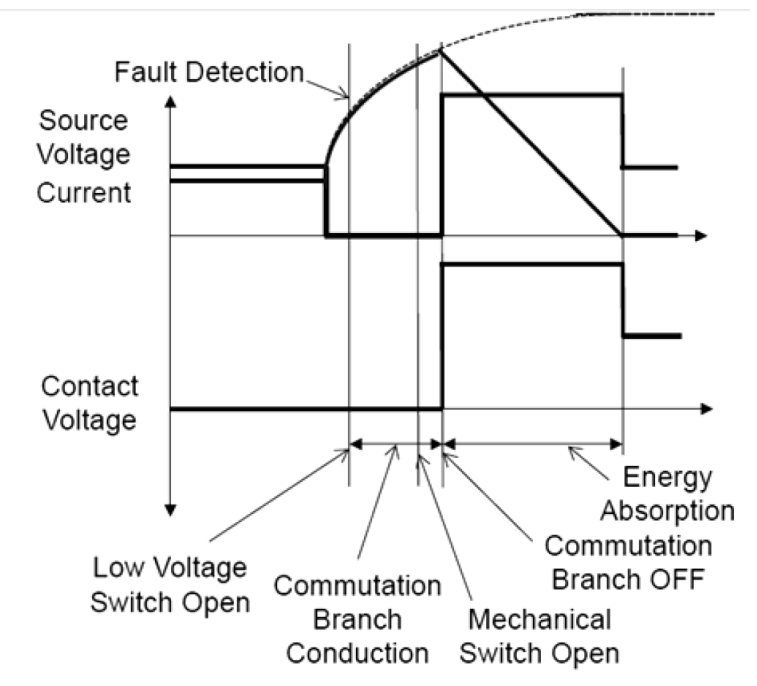

Fig. 2: Hybrid DC breaker sequence [9]

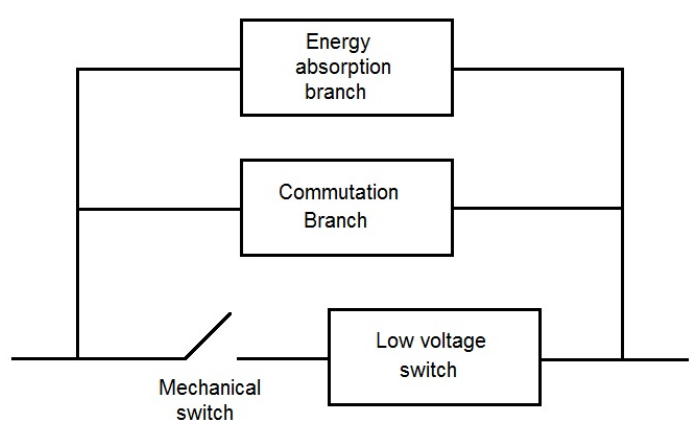

Fig. 3: Typical hybrid DC breaker construction

\subsection{Voltage capability}

An important requirement of a DC breaker is the ability to create a counter voltage larger than the grid voltage in order to demagnetize the grid inductance and to drive the short circuit current to zero. From Fig. 4 the counter voltage $\left(U_{C}\right)$ can be written as:

$$
U_{C}=U_{D C}-U_{\text {Breaker }}=L_{D C} \cdot \frac{d i_{D C}}{d t}+I_{D C} \cdot R_{D C}
$$

with $U_{D C}$ the voltage in the grid, $U_{\text {breaker }}$ the voltage over the breaker and $R_{D C}$ and $L_{D C}$ the resistance and inductance of the grid respectively.

The counter voltage in the hybrid breaker is produced by an arrester in the energy absorption branch of Fig. 3. A shorter fault clearance requires a higher voltage dimensioning of the arrester. On the other hand, an increase of the protective level of the arrester will result in higher pole to pole voltage rating. 


\subsection{Current breaking capability}

The maximal current breaking capacity is determined by the dimensioning of the commutation branch of the hybrid breaker. Before the breaker opens, the full grid voltage stands across the resistance and inductance of the transmission line. The voltage over the DC breaker during the fault in Fig. 4, is given by:

$$
U_{\text {breaker }}=R_{D C} \cdot I_{S C}+L_{D C} \cdot \frac{d I_{S C}}{d t}
$$

From (3), the maximum breaker current depends on the network parameters and can be determined by [6]:

$$
I_{S C}=\frac{U_{S C}}{R} \cdot\left(1-e^{\frac{t \cdot R_{D C}}{L_{D C}}}\right)
$$

, with $t$ the time after the fault occurrence. The maximal current through the breaker thus depends on the interruption time. It can be seen from (4) that the maximum current for a given interruption time can be diminished by increasing the network inductance, as this increases the time constant of the current increase.

\subsection{Switching time}

The switching time is defined as the time from the fault occurrence and the interruption of the DC fault by the DC breaker. With a hybrid breaker, the switching time depends on the fault detection, the opening of the low voltage switch, conduction time of the commutation branch, opening of the mechanical switch and the interruption of the commutation branch of the hybrid breaker. A higher switching time increases the DC current and the dissipated energy requirement of the arrester in the hybrid breaker.

\subsection{Energy capability}

The stored energy, of which a large part is stored in the network inductances (4), has to be dissipated by the breaker. The energy dissipation can for example be performed by a surge arrester. From (5), it can be concluded that the placement of series inductors in the energy dissipation requirement of the breaker.

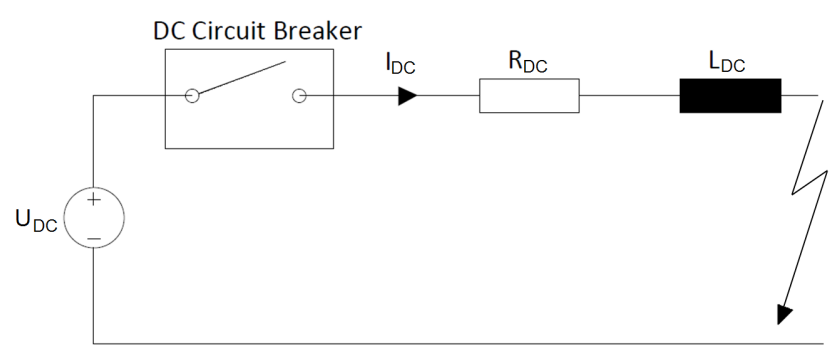

Fig. 4: Simplified DC circuit.
Table 1: Dataset of the network in Fig. 5.

\begin{tabular}{c|c}
$\mathrm{U}$ & $320[\mathrm{kV}]$ \\
$\mathrm{P}$ & $100[\mathrm{MW}]$ \\
$\mathrm{R}$ & $0.0121[\Omega / \mathrm{km}]$ \\
$\mathrm{C}$ & $0.2961[\mu \mathrm{H} / \mathrm{km}]$ \\
$\mathrm{L}$ & $0.1056[\mathrm{mH} / \mathrm{km}]$
\end{tabular}

$$
E=\frac{L \cdot I_{S C}^{2}}{2}
$$

the placement of inductors is therefore a trade-off between the reduction in the fault current and dissipated energy.

\section{Simulation network}

For the simulation in this paper, a four-terminal network from Fig. 5 is chosen. The data of this network is shown in Table 1. This radial network allows a close observation of the fault propagation in a HVDC grid. It can be considered as a part of a larger HVDC grid. However, due to the propagation delay and attenuation of the travelling waves, the influence of remote parts of the grid has been assumed to be negligible.

The underground cable model is simulated by a frequency dependent distributed parameters model. The half bridge MMC converters are simulated with the equivalent model described in [10] and the DC breaker model is based on the model proposed in [11]. The mechanical switching branch and commutation branch are simplified by an ideal switch with an artificial delay to simulate the detection and commutation time. The third parallel branch, the absorption branch is modelled by an arrester. The maximum voltage for the demagnetization is chosen to be $50 \%$ higher than the nominal grid voltage according to [6]. Therefore, the arrester is simulated with a cut-off voltage of 1.5 p.u.. The fault is considered to be detected when the fault is higher than 1.5 p.u. and the voltage lower than 0.8 p.u.. For relays close to the fault, this comes down to immediate fault detection. For relays further from the fault, detection can be slightly delayed due to the propagation and attenuation of the waves.

An inductor is placed at each side of a transmission line to limit the rate of rise of the fault current.

\section{Sizing of the series inductor}

In this paper, the reduction of the maximal breaking current and the dissipated energy in the arrester by respectively series inductor placement and different protection scheme are examined. The breaking current is reduced by placing inductors in the network to limit the fault currents. Fig. 6 shows the maximal breaking current through the breaker for different inductor sizes and different switching times for the network of Fig. 5. 

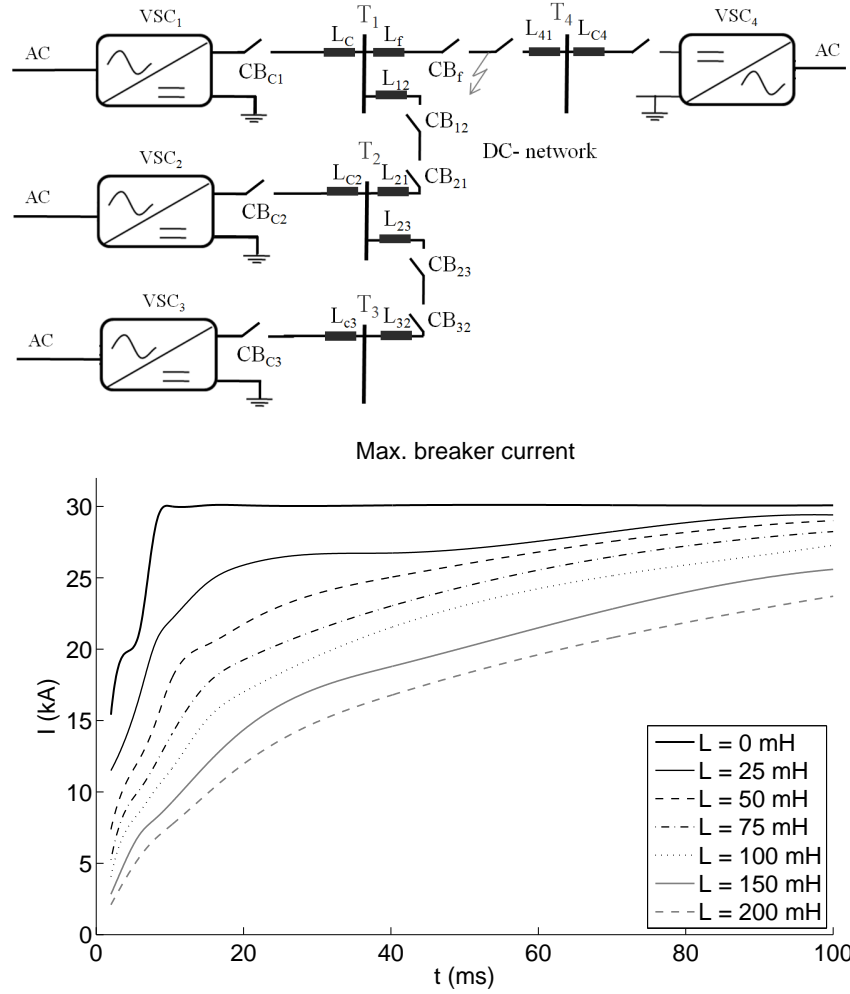

Fig. 6: Maximum breaker current for differnet inductor sizes and switching times for a four-terminal radial network.

If the maximal breaking current of a DC breaker and its maximal switching time is known, the minimal required inductor size in the network can be determined. Next, the arrester energy of the hybrid breaker is examined for the different protection schemes. The goals in this paper is to decrease the dissipated energy requirement of the DC breaker by using different protection schemes. This is achieved by comparing breakers with a different maximum breaking current and different protection schemes.

The study starts from a full selective protection scheme (FSP) as this is the common protection scheme as used in AC grids. DC breakers with a maximal breaker current of $10 \mathrm{kA}, 15 \mathrm{kA}$ and $20 \mathrm{kA}$ and a switching time of 2, 5, 10 and $20 \mathrm{~ms}$ are studied. The switching time is limited to $20 \mathrm{~ms}$ as a longer time requires very large inductors which is impractical and increases the cost of the HVDC grid. For each case, the required inductor size value can be chosen from Fig. 6. The minimal required inductor size for the different cases is given in table 2 .

\section{Protection schemes}

\subsection{Full selective protection}

The sequence of a selective protection is shown in Fig. 7. If a fault occurs at time $t_{f}=0$, it takes some time for the relay to detect the fault $\left(t_{d}\right)$. Next, the relay determines the location of the fault $t_{L}$ and if the fault is located within the operating range of the breaker, it will trip at $t_{I}$. Meanwhile, other breakers in
Table 2: Inductor sizes for different switching time and current ratings.

\begin{tabular}{c|c|c|c} 
Breaker time & $10 \mathrm{kA}$ & $15 \mathrm{kA}$ & $20 \mathrm{kA}$ \\
\hline $2 \mathrm{~ms}$ & $34[\mathrm{mH}]$ & $13[\mathrm{mH}]$ & $0[\mathrm{mH}]$ \\
$5 \mathrm{~ms}$ & $70[\mathrm{mH}]$ & $25[\mathrm{mH}]$ & $0[\mathrm{mH}]$ \\
$10 \mathrm{~ms}$ & $125[\mathrm{mH}]$ & $61[\mathrm{mH}]$ & $37.5[\mathrm{mH}]$ \\
$20 \mathrm{~ms}$ & $250[\mathrm{mH}]$ & $140[\mathrm{mH}]$ & $70[\mathrm{mH}]$
\end{tabular}

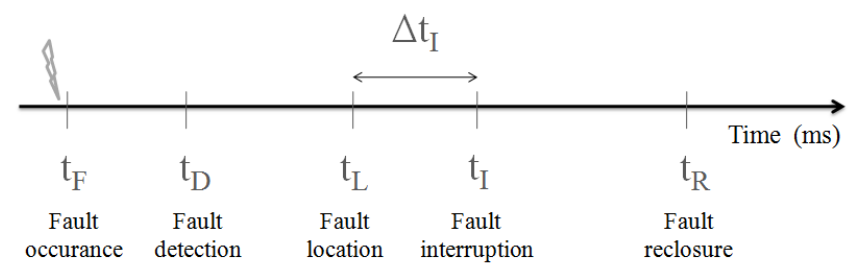

Fig. 7: Selective protection time sequence.

the network, which are not located on the faulted line are not allowed to trip to the fault. These breakers notice at $t_{L}^{\prime}$ that the fault occurs outside their operation range and will not trip.

The advantage of the selective protection method is that only the faulted line trips, which limits the impact of fault interruption on the healthy part of the grid. The main disadvantage of the selective protection approach is that each breaker needs to be dimensioned to interrupt the fault current.

\subsection{Open grid protection}

An alternative protection method for HVDC grids has been proposed in [1]. The open grid protection scheme is characterized by the time sequence in Fig. 8. The difference with the selective approach is the order of fault location $t_{l}$ and interruption $t_{I}$. The OGP will first interrupt the fault and will afterwards detect the location of the fault. The main goal of the proposed open grid protection (OGP) is the distribution of the breaker energy requirement over different breakers. The main advantage is the relaxation of breaker requirements as fault current interruption is shared between different breakers as the non selectivity results in the reaction of multiple breakers to the fault. The disadvantages are unpredictability of the tripping sequence and possible larger de-energization of the network. Additionally, the location of the fault still has to be determined on the post-fault signal.

\section{Results}

In this section, first the detection and tripping time of the different breakers for the two protection schemes are shown for a case with a series inductor of $25 \mathrm{mH}$ and a switching time of $2 \mathrm{~ms}$. The energy reduction of the two protection methods depends on the size of the series inductors and the switching times. The DC breaker energies are presented for a different 


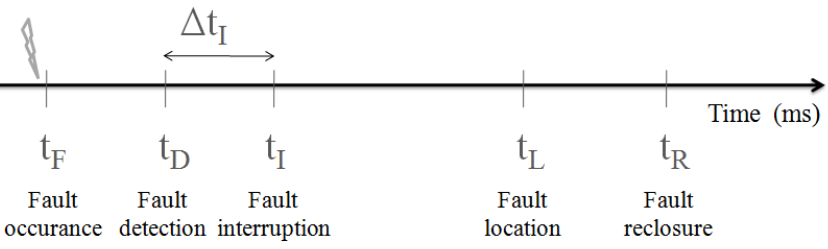

Fig. 8: Open grid protection time sequence.

cases with DC breaker ratings of 10kA, $15 \mathrm{kA}$ and $20 \mathrm{kA}$. the switching time is varied from $2 \mathrm{~ms}, 5 \mathrm{~ms}, 10 \mathrm{~ms}$ and $20 \mathrm{~ms}$.

\subsection{Detection and tripping sequence}

The fault detection of the relays placed on both sides of the transmission lines of the network in Fig. 5 is shown in Fig. 9.

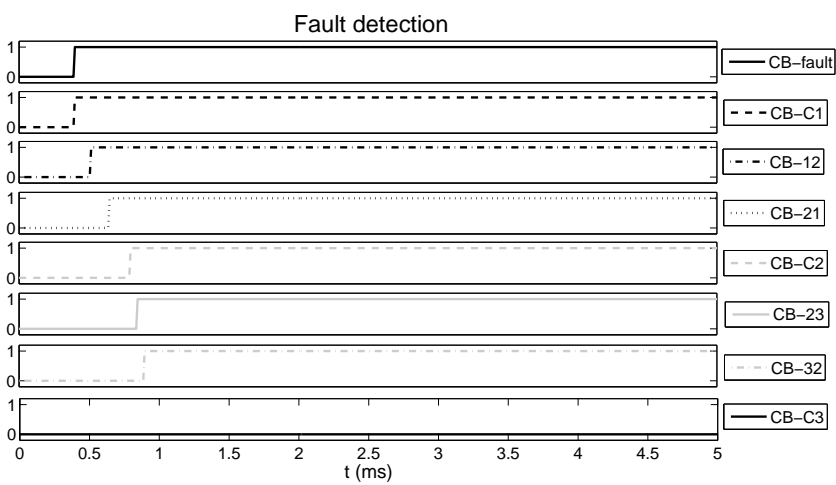

Fig. 9: Fault detection of the DC breaker in a four-terminal radial network of Fig. 5. without breaker action

The tripping sequence of the breaker on the network for a FSP are shown in Fig. 10. As needed for a selective protection system, only the breaker CB-fault trips.

Fig. 11 shows the tripping sequence of the breaker on the network for the open grid protection. The tripping of the breakers corresponds with the fault detection in Fig. 9 with a delay of $2 \mathrm{~ms}$. Circuit breaker $C B_{C 3}$ does not detect the fault, nor trips. This is due to the attenuation of the fault as it propagates through the network. The division of the energy over multiple breakers is determined by how fast the 'assistant breakers' open the fault. From the fault detection of the breaker $C B_{\text {fault }}$ until interruption, $2 \mathrm{~ms}$ has passed. If a second breaker $\left(C B_{12}\right.$ and/or $C B_{C 1}$ ) opens during these $2 \mathrm{~ms}$, the buildup energy in $C B_{\text {fault }}$ can be divided over multiple breakers. If a breaker opens later than the $2 \mathrm{~ms}$ interruption time of $C B_{\text {fault }}$, tripping of this breaker does not contribute to an energy reduction in $C B_{\text {fault }}$. It is therefore important that the assistant breaking occurs as fast as possible to to maximize the division of energy over multiple breakers. The fast detection of the fault by the assistant breakers can be hampered by a long propagation time for long transmission lines and longer fault detection

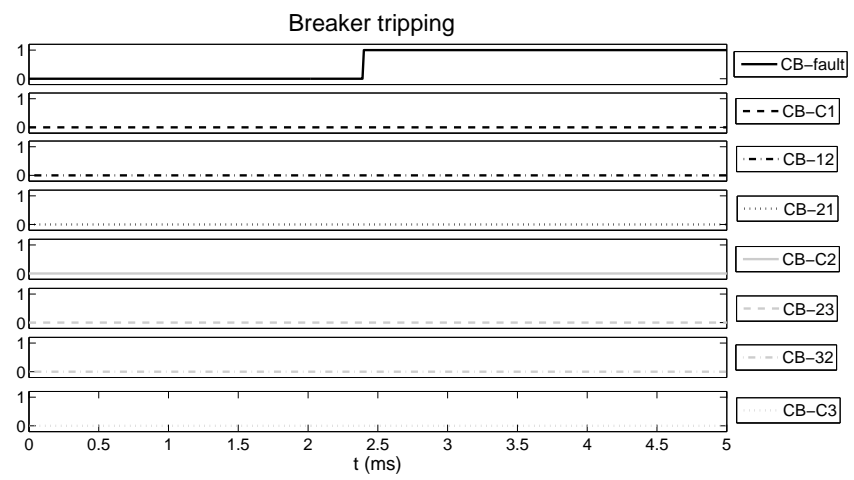

Fig. 10: Tripping sequence of the breakers on the fourterminal radial network of Fig. 5 with a full selective protection scheme

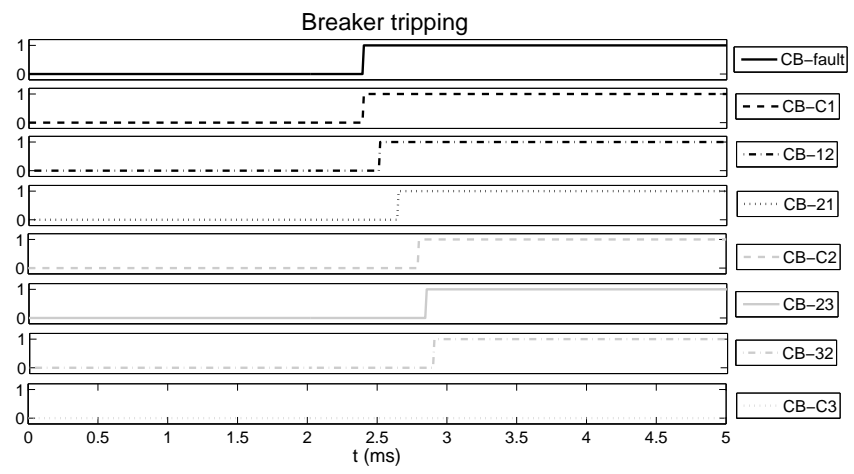

Fig. 11: Tripping sequence of the breakers on the fourterminal radial network of Fig. 5 with a open grid protection scheme

time due to the lower rate of increase of the fault current if additional inductors are placed. The division of energy therefore decreases for larger inductor values provided that each breaker trips by its own detection logic. This OGP is thus most optimal for breakers with higher fault breaking capabilities and low inductor values.

\subsection{DC breaker energy}

The energy dissipation for different rated DC breakers and different switching times is shown in Fig. 12. For both protection schemes, the arrester energy increases with switching time. This shows that it is favourable to interrupt fault currents in early stages as the fault current keeps increasing. Furthermore, breaker energy decreases with current interruption capability due to lower requirements for inductor sizes, which leads to less stored energy in case of faults.

The OGP gives a reduction in the arrester energy requirement compared to the FSP due to the opening of multiple breakers. In Fig. 13, the energies of the different breakers of the network in Fig. 5 are shown. The extent to which a breaker will aid in dissipating energy depends on the location and action time of the breaker. The breakers close to the fault will 

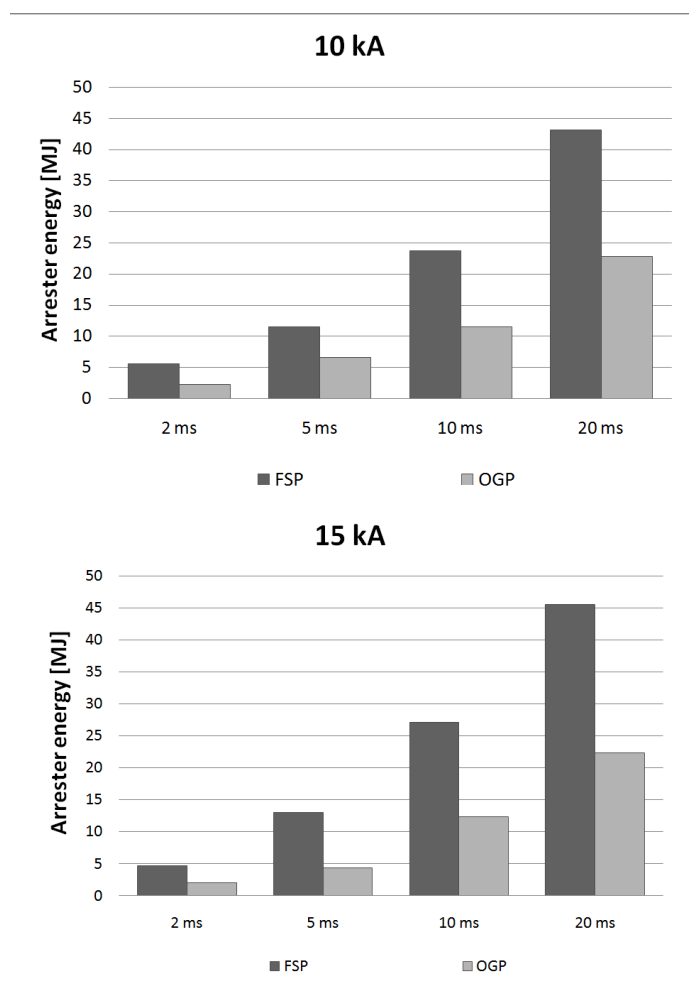

$20 \mathrm{kA}$

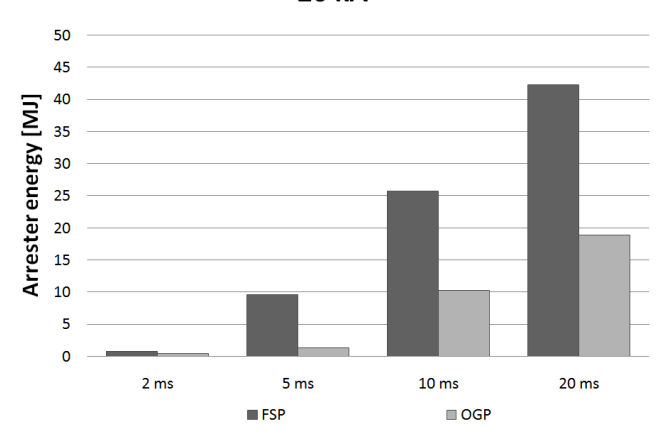

Fig. 12: Arrester energy of breaker $C B_{\text {fault }}$ on a fourterminal radial network for different protection schemes (FSP and OGP) with varying breaker interruption capabilities.

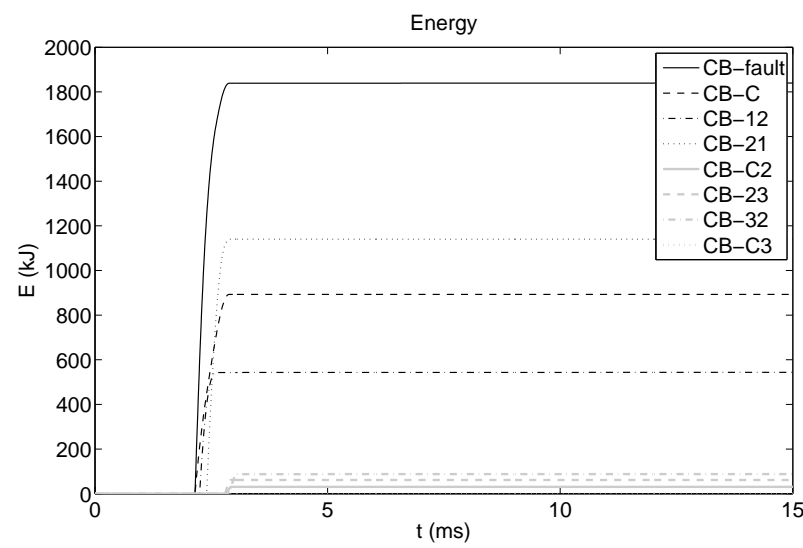

Fig. 13: Energy of each breaker in the network of Fig. 5 for the OGP scheme with $\Delta t_{I}=2 \mathrm{~ms}$.

contribute to an energy reduction in the faulted line breaker $C B_{\text {fault }}$. For the breakers on terminal 2 and 3 in Fig. 5, the propagation delay and detection delay (due to the smoothing of the fault currents by the inductors in the network) exceed the time it takes for the breaker on the line $\left(C B_{\text {fault }}\right)$ to close. Although these breakers eventually trip, they do not contribute to the reduction of breaker energy of breaker $C B_{\text {fault }}$. For networks with shorter transmission lines, the propagation delay decreases. Depending on the length, the breakers on terminal 2 may detect the fault within the breaking time of the faulted line breaker $C B_{\text {fault }}$ and therefore contribute to an energy reduction in $C B_{\text {fault }}$.

In the FSP, all the energy of the breakers in Fig. 13 has to be dissipated only by breaker $C B_{\text {fault }}$. The reduction of energy by the OGP in Fig. 12 increases for longer switching times as the overall energy requirement increase.

\section{Conclusion}

This paper investigates breaker requirements for hybrid HVDC breakers, especially regarding energy dissipation which is needed to dissipate energy stored in the grid after a fault. The fundamental parameter that determines breaker requirements is the interruption time. A decrease in interruption time both decreases maximum current to be interrupted and energy to be dissipated. Therefore, this paper investigated breaker requirements for two protection methods, which are a selective protection method and an open grid protection method. For both protection schemes, a sensitivity analysis towards breaker parameters such as maximum interruption capability and interruption time is performed. Together with the breaker parameters, series inductor sizes were determined.

From the comparison of the different protection schemes and their influence on the arrester energy, it can be concluded that the open grid protection (OGP) achieves a reduction of the dissipated energy requirement of DC breakers, compared to the full selective protection (FSP). The reduction potential de- 
pends on the delay of the tripping of the assistant breakers to the tripping of the breaker at the faulted line end. When breakers trip simultaneously, the reduction in dissipated energy is maximized. The tripping delay is caused by propagation delay of traveling waves over a cable and slower detection due to attenuation of the wave due to series inductors. For large scale HVDC grids with long cables, only the opening of adjacent breakers contributes to an energy reduction in the main breaker.

To reduce the detection delay between the breakers, smaller inductor values are advantageous for these protection methods. A DC breaker with a OGP therefore requires a higher current breaking capability compared to the case with larger inductor values.

In future work, the open grid protection can be improved by avoiding the tripping of breakers located further from the fault as they do not contribute to an energy reduction in the breaker on the faulted line. The energy reduction is then only divided through the breakers connected to terminal 1. The tripping sequence will be identical as Fig. 8, but is limited to breakers $C B_{\text {fault }}, C B_{12}$ and $C B_{C 1}$.

A second improvement can be made by optimising the energy reduction between the different breakers. This energy reduction is limited by the synchronicity of the switching of the different breakers which differs because the propagation and detection delays causes different fault detection times in the network. By synchronising the switching of the appropriate breakers, an maximum energy reduction in the breaker on the faulted line can be achieved.

\section{References}

[1] C. Barker and R. Whitehouse, "An alternative approach to HVDC grid protection," in Proc. IET ACDC 2012, Birmingham, UK, 4-6 Dec. 2012, 6 pages.

[2] D. Vishawakarma and B. Ram, Power system protection and switchgear. New Delhi, India: Tata McGraw-Hill, 1995.

[3] D. Van Hertem, M. Ghandhari, J. Curis, O. Despouys, and A. Marzin, "Protection requirements for a multiterminal meshed DC grid," in CIGRE 2011 Bologna Symp., Bologna, Italy, 13-15 Sep. 2011, 8 pages.

[4] L. V. Bewley, "Travelling waves on electric power systems," in Bull Amer Math, vol. 8, April 1942, pp. 527538.

[5] L. van der Sluis, Transients in Power Systems. Hoboken, NJ, USA: John Wiley \& Sons, Inc., 2001.

[6] C. Meyer, M. Kowal, and R. De Doncker, "Circuit breaker concepts for future high-power DCapplications," in Proc. IEEE Ind. Applic. Conf. 2005, vol. 2, Hong Kong, China, 2-5 Oct. 2005, pp. 860-866.
[7] C. Franck, "HVDC circuit breakers: A review identifying future research needs," vol. 26, no. 2, pp. 998-1007, 2011.

[8] J. Häfner, B. Jacobson, M. Callavik, and A. Blomberg, "The hybrid HVDC breaker an innovation enabling reliable HVDC grids," in IEEE Trans. Pow. Del., November 2012.

[9] R. Whitehouse, "HVDC breakers and grid protection: Why, what and when?" in Ku Leuven EES - UETP, 30 November 2013.

[10] U. Gnanarathna, A. Gole, and R. Jayasinghe, "Efficient Modeling of Modular Multilevel HVDC Converters (MMC) on Electromagnetic Transient Simulation Programs," vol. 26, no. 1, pp. 316-324, 2011.

[11] J. Häfner and B. Jacobson, "Proactive Hybrid HVDC Breakers: A key innovation for reliable HVDC grids," in CIGRÉ Bologna Symp., Bologna, Italy, 13- 15 Sep. 2011, 8 pages. 